\title{
Biomechanical assessment of two different surgical treatments for the correction of flat foot
}

\author{
Lisa Berti ${ }^{1}$, Giulia Celin ${ }^{1}$, Paolo Caravaggi ${ }^{{ }^{*}}$, Sandro Giannini ${ }^{1,2}$, Alberto Leardini $^{1}$ \\ From 4th Congress of the International Foot and Ankle Biomechanics (i-FAB) Community \\ Busan, Korea. 8-11 April 2014
}

\section{Introduction}

The flat foot is a very frequent deformity in orthopedics and can be observed at different levels of severity already in childhood and infancy. The possible functional alterations associated with flat feet are not fully established. These can result in critical clinical consequences, such as secondary deformities of the forefoot and lower limb, pain and muscle fatigue. The prescription of orthotics or indication for surgical interventions are still much debated. A diagnosis based only on foot morphology is not sufficient to decide the therapeutic approach. In fact, the degree of severity of the deformity and the effects of treatments require also careful functional assessment. This study aims at investigating by means of movement analysis the effects of two different surgical treatments for severe flat foot.

\section{Methods}

Ten children $(11.3 \pm 1.6$ yrs, $19.7 \pm 2.8 \mathrm{BMI})$ were operated for the correction of flat foot $[1,2]$ in both feet. One foot was corrected with a calcaneo-stop method, i.e. a screw implanted into the calcaneus, and the other with an endoprosthesis implanted into the sinus-tarsi. Gait analysis was performed pre- and 12 month post-operative, using a 8-camera motion system (Vicon, UK). An established protocol for lower limb [3] and a multi-segment foot kinematic analysis [4] were used to calculate joint rotations and moments during three walking trials for each subject.

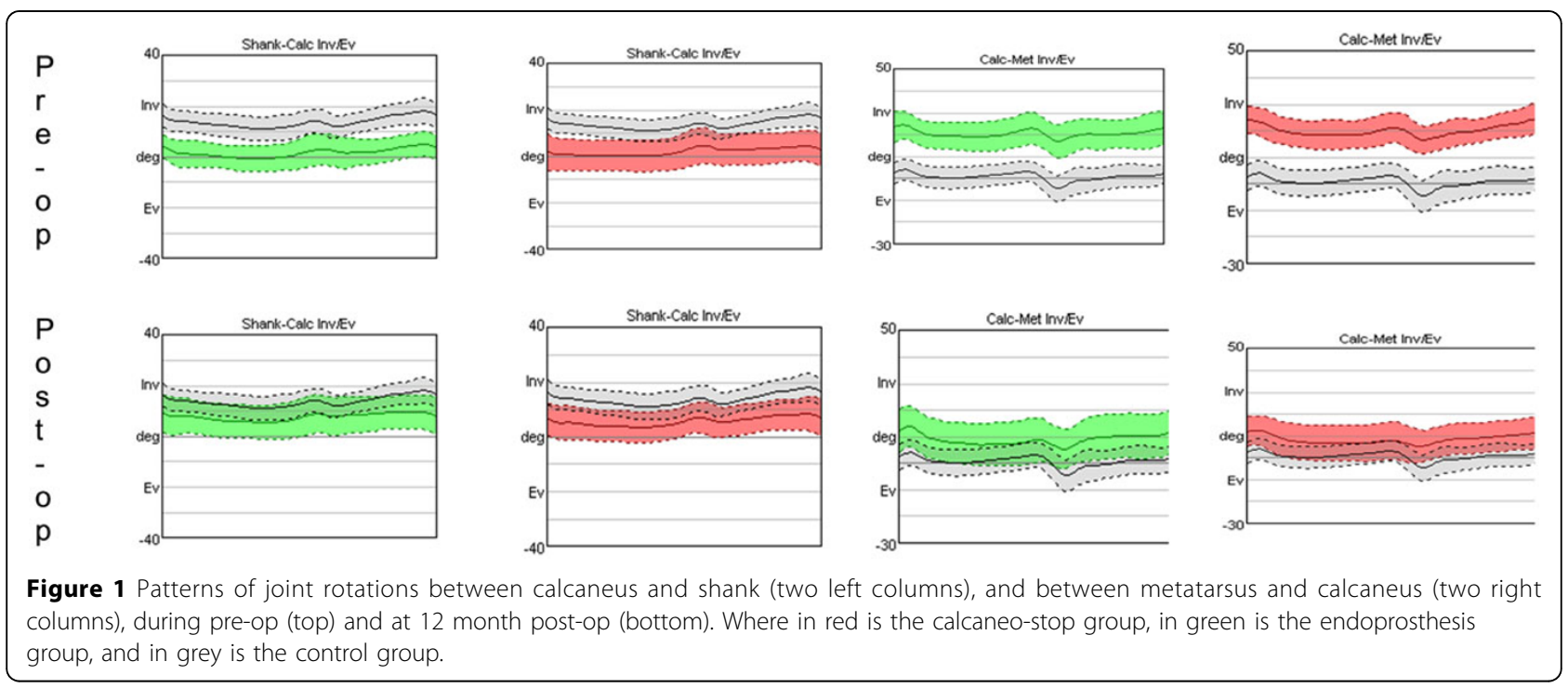

'Movement Analysis Laboratory, Istituto Ortopedico Rizzoli, Bologna, 40136,

Italy

Full list of author information is available at the end of the article

(C) 2014 Berti et al; licensee BioMed Central Ltd. This is an Open Access article distributed under the terms of the Creative Commons 


\section{Results}

Significant differences in standard X-ray measurements were observed between pre- and post-op, but not between feet. Analysis of the kinematic variables revealed important functional corrections. In particular, joint rotations at the ankle (Figure 1, left) and those between the metatarsus and calcaneus segments (Figure 1, right) improved significantly between pre- and post-op. Ground reaction force showed that the deficits in propulsion and stability pre-op were resolved in both feet, i.e. with both implants.

\section{Conclusion}

The combined lower limb and multi-segment foot kinematics analyses was found adequate and provided a thorough and accurate functional assessment of the entire limbs. Both surgical treatments enabled good restoration of the normal kinematics of the foot and of the lower limb joints. This population will be monitored further to assess the functional progresses in time; preservation, or even improvement, of these results, are expected.

\section{Authors' details}

${ }^{1}$ Movement Analysis Laboratory, Istituto Ortopedico Rizzoli, Bologna, 40136, Italy. ${ }^{2} 1^{\text {st }}$ Division of Orthopedic Surgery, Istituto Ortopedico Rizzoli, Bologna, 40136, Italy.

Published: 8 April 2014

\section{References}

1. Giannini $S$, et al: Surgical treatment of flexible flatfoot in children: a four year follow-up study. J Bone Joint Surg Am 2001, 83-A(Suppl 2 Pt 2):73-9.

2. Roth $S$, et al: Minimally invasive calcaneo-stop method for idiopathic, flexible pes planovalgus in children. Foot Ankle Int 2007, 28(9):991-5.

3. Leardini $A$, et al: A new anatomically based protocol for gait analysis. Gait Posture 2007, 26(4):560-71.

4. Leardini $A$, et al: Rear-foot, mid-foot and fore-foot motion during the stance phase of gait. Gait Posture 2007, 25(3):453-62.

doi:10.1186/1757-1146-7-S1-A52

Cite this article as: Berti et al.: Biomechanical assessment of two different surgical treatments for the correction of flat foot. Journal of Foot and Ankle Research 2014 7(Suppl 1):A52.

\section{Submit your next manuscript to BioMed Central} and take full advantage of:

- Convenient online submission

- Thorough peer review

- No space constraints or color figure charges

- Immediate publication on acceptance

- Inclusion in PubMed, CAS, Scopus and Google Scholar

- Research which is freely available for redistribution

Submit your manuscript at www.biomedcentral.com/submit 